\title{
Desempenho de um fertilizante mineral misto produzido a partir de fosfato natural sedimentar
}

O objetivo deste trabalho foi avaliar a eficiência de um fertilizante mineral misto (FMM) produzido com fosfato natural sedimentar adicionado de calcário e borra de enxofre, em relação a produção de matéria seca da parte aérea e acúmulo de P de plantas de milho e feijão, comparado com o fertilizante superfosfato simples em diferentes condições de incubação do solo com calcário. $O$ experimento foi conduzido em casa de vegetação sendo realizados três cultivos sucessivos na seguinte ordem: milho, feijão, milho. As plantas foram cultivadas em vasos plásticos contendo $3 \mathrm{~kg}$ de amostras de solo classificado como Latossolo VermelhoAmarelo textura argilosa. $O$ delineamento experimental foi em blocos casualizados, em esquema fatorial $2 \times 4+1$, sendo dois fertilizantes fosfatados (superfosfato simples - SSP e FMM), quatro doses de P2O5 (25, 50, 100 e $150 \mathrm{mg}$ de P2O5 dm-3), e o tratamento controle, sem aplicação de P. Foram montados dois experimentos sendo um com solo incubado com calcário e outro com solo não incubado. Foram avaliados a produção de massa seca da parte aérea (MSPA) e o acúmulo de fósforo da parte aérea (APPA). Nas condições avaliadas, os resultados mostraram que o SSP foi mais eficiente que FMM na produção de massa seca e no acúmulo de P, principalmente quando o solo foi incubado com calcário. As maiores respostas da MSPA e do APPA em relação ao aumento da dose do FMM foram observadas em solo não incubado com calcário. A incubação prévia do solo usando calcário dolomítico diminuiu a eficiência relativa de FMM em relação ao SSP. O SSP aplicado em condição de solo incubado proporcionou desempenho semelhante na MSPA e APPA em relação as SSP aplicado em condição de solo não incubado.

Palavras-chave: Adubação Fosfatada; Calagem; Fonte de Fósforo; Pó de Rocha Fosfática; Incubação do Solo.

\section{Performance of a mixed mineral fertilizer produced from sedimentary natural phosphate}

\begin{abstract}
The objective of this work was to evaluate the efficiency of a mixed mineral fertilizer (MMF), produced with natural sedimentary phosphate mixed with limestone and sulfur sludge, in relation to shoot dry matter production and $P$ accumulation of corn and bean plants, compared to the fertilizer simple superphosphate under different conditions of soil incubation with limestone. The experiment was conducted in a greenhouse and three successive crops were carried out in the following order: corn, bean, corn. The plants were grown in plastic pots containing $3 \mathrm{~kg}$ of soil samples. The experimental design was in randomized blocks, in a factorial scheme $2 \times 4+1$, two phosphate fertilizers (single superphosphate - SSP and MMF), four doses of P2O5 (25, 50, 100 and $150 \mathrm{mg}$ of P2O5 dm-3 soil), and the contro treatment, without application of P. Two experiments were carried out, one with soil incubated with limestone and the other with unincubated soil. Shoot dry mass production (SDM) and the shoot phosphorus accumulation (SPA) were evaluated. Under the evaluated conditions, the results showed that the SSP was more efficient than MMF in dry mass production and P accumulation, especially when the soil was incubated with limestone. The highest responses of MSPA and APPA in relation to MMF dose increase were observed in soil not incubated with limestone. Previous incubation of the soil using dolomitic limestone decreased the relative efficiency of MMF in relation to SSP. The SSP applied in incubated soil condition provided similar performance in the MSPA and APPA in relation to the SSP applied in unincubated soil.
\end{abstract}

Keywords: Phosphate Fertilization; Liming; Phosphorus Source; Phosphate Rock Powder; Soil Incubation.

Topic: Ciências do Solo

Reviewed anonymously in the process of blind peer
Received: 03/08/2020

Approved: 17/09/2020
Ricardo de Castro Dias (iD)

Universidade Federal Rural do Rio de Janeiro, Brasil http://lattes.cnpq.br/1167182108255818 http://orcid.org/0000-0003-2300-1121

ricardodiasrcd2@ufrri.br

João Victor dos Santos Caldas (ii)

Universidade Federal Rural do Rio de Janeiro, Brasil http://lattes.cnpq.br/7262281161723213 http://orcid.org/0000-0002-7885-6939

jvictorscaldas@gmail.com

\section{José Carlos Polidoro (iD}

Embrapa Solos, Brasil

http://lattes.cnpq.br/4745932943641979

http://orcid.org/0000-0003-4049-5768

jose.polidoro@embrapa.br

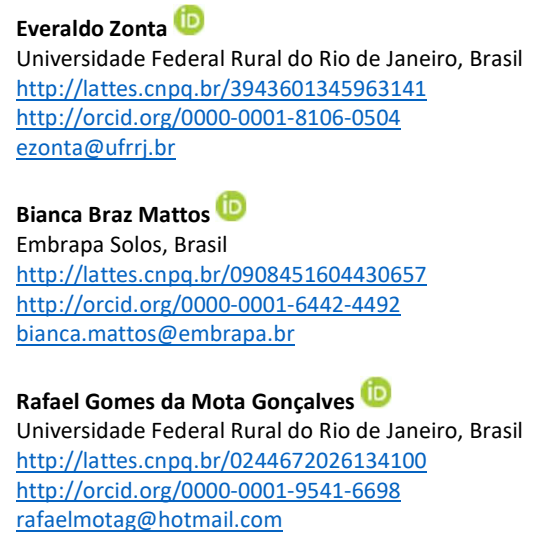

Paulo César Teixeira

Embrapa Solos, Brasil

http://lattes.cnpq.br/6153040121133266 http://orcid.org/0000-0001-8455-7057

paulo.c.teixeira@embrapa.br
DOI: 10.6008/CBPC2179-6858.2020.005.0003

\section{Referencing this:}

DIAS, R. C.; CALDAS, J. V. S.; POLIDORO, J. C.; ZONTA, E.; MATTOS, B. B.; GONÇALVES, R. G. M.; TEIXEIRA, P. C.. Desempenho de um fertilizante mineral misto produzido a partir de fosfato natural sedimentar. Revista Ibero Americana de Ciências Ambientais, v.11, n.5, p.21-31, 2020. DOI: http://doi.org/10.6008/CBPC21796858.2020 .005 .0003 


\section{INTRODUÇÃO}

O fósforo ocorre na natureza principalmente como fosfato e é encontrado nas rochas denominadas fosfáticas, como as apatitas, que contém também cálcio. Desempenha papel primordial na gestão da produção agrícola, sendo aplicado ao solo com fins de fertilização. Atualmente, o elemento tem sido motivo de discussão de pesquisadores do mundo todo, devido à depleção de jazidas de fósforo e ameaça à segurança alimentar global (ASHLEY et al., 2011; COOPER et al., 2011; GEISSLER et al., 2018; KOPPELAAR et al., 2013; LEGHARI et al., 2016).

É estimado que aproximadamente $70 \%$ das reservas de rocha fosfática estão concentradas em uma área restrita do globo terrestre, correspondente ao Marrocos e Saara Ocidental. Além disso, o ácido sulfúrico que possui papel fundamental na fabricação de fertilizantes fosfatados é produzido predominantemente em cinco países: China, EUA, Rússia e Marrocos. Esses cinco países combinados, juntamente com o Saara Ocidental, produzem aproximadamente $76 \%$ da rocha fosfática extraída anualmente em todo o mundo, e controlam cerca de $42 \%$ do mercado de ácido sulfúrico. Neste cenário, o Brasil contribui com 2,2\% da mineração mundial de rocha fosfática, sendo detentor de aproximadamente $2,5 \%$ das reservas conhecidas em todo o mundo (USGS, 2020).

Além da insuficiente produção de fertilizantes fosfatados e das reservas limitadas de rochas fosfáticas, o que acarreta em importação de cerca de 63,3 \% do fertilizante fosfatado consumido no Brasil (ANDA, 2019), o Brasil possui solos com baixa disponibilidade natural de $\mathrm{P}$, com acidez elevada e presença de altos níveis de sesquióxidos de Fe e Al (BROGGI et al., 2010). O fósforo (P) é o nutriente mais limitante para a produtividade de biomassa em solos tropicais, e a baixa reversibilidade da adsorção desse elemento ao solo (NOVAIS et al., 1999) diminui a eficiência no seu aproveitamento pelas plantas em solos altamente intemperizados. O P apresenta forte interação com componentes minerais da fase sólida de solos intemperizados, formando complexos de alta energia e de difícil reversibilidade. Sendo assim, grande parte do $\mathrm{P}$ aplicado via fertilizante não é disponibilizado ao vegetal, pois é fortemente adsorvido por componentes minerais da fase sólida do solo, ou precipita como compostos de baixa solubilidade (BRAOS et al., 2015). Com a adubação fosfatada, busca-se elevar a disponibilidade de $\mathrm{P}$ no solo a níveis considerados satisfatórios, o que resultará num aumento do potencial produtivo da área, quando esta apresentar condições favoráveis de suprimento de água e dos demais nutrientes (SOUSA et al., 2016).

Uma das estratégias adotadas pelas instituições de pesquisa para amenizar a dependência política e econômica para a obtenção de fertilizantes fosfatados vem sendo o desenvolvimento e validação agronômica de novos fertilizantes produzidos a partir de matérias primas alternativas de ocorrência nacional. Dentre estas fontes há os fosfatos naturais sedimentares, normalmente com mais baixo teor de $\mathrm{P}_{2} \mathrm{O}_{5}$, para serem utilizados na indústria convencional de fertilizantes. Um fertilizante mineral misto (FMM), produzido com matéria prima exclusivamente nacional, constituído de rocha fosfática sedimentar, extraída de jazidas da região de Arraiais - TO com $12 \%$ de $\mathrm{P}_{2} \mathrm{O}_{5}$ total, 'borra' de enxofre (que contém $60 \%$ de $\mathrm{S}$ elementar) e calcário dolomítico, tem sido usado em algumas regiões do Brasil, especialmente na região do MATOPIBA. 
Em condições de pH mais elevado, a dissolução dos fosfatos naturais reativos é significativamente mais lenta e a eficiência agronômica inicial inferior, independentemente da forma de aplicação (SOUSA et al., 2016). Diante do exposto, o presente trabalho teve como objetivo avaliar a eficiência agronômica do FMM produzido com fosfato natural sedimentar adicionado de calcário e borra de enxofre em relação a produção de matéria seca e acúmulo de $\mathrm{P}$ de plantas de milho e feijão, comparado com o fertilizante superfosfato simples em diferentes condições de incubação do solo com calcário.

\section{MATERIAIS E MÉTODOS}

O experimento foi conduzido em casa de vegetação, localizada no município de Seropédica - RJ ( $22^{\circ}$ $45^{\prime} 33^{\prime \prime}-\mathrm{S}$ e $43^{\circ} 41^{\prime} 50^{\prime \prime}-0$ ). Foram utilizadas amostras de um solo classificado como Latossolo VermelhoAmarelo (LVA) textura argilosa (SANTOS et al., 2018), coletadas no município de Paula Cândido/MG, na camada de 0-20 cm de profundidade. Após a coleta, as amostras de terra foram secas ao ar, peneiradas em peneira com abertura de malha de $4 \mathrm{~mm}$, e caracterizadas quimicamente, conforme Teixeira et al. (2017). Os resultados da análise química estão apresentados na Tabela 1. As amostras de LVA possuíam $380 \mathrm{~g} \mathrm{~kg}^{-1}$ de argila, $100 \mathrm{~g} \mathrm{~kg}^{-1}$ de silte e $520 \mathrm{~g} \mathrm{~kg}^{-1}$ de areia apresentando, portanto, textura argilosa.

Tabela 1: Atributos químicos ${ }^{1 /}$ de amostras de Latossolo Vermelho Amarelo textura argilosa coletadas na camada de 0$20 \mathrm{~cm}$ de profundidade.

\begin{tabular}{|c|c|c|c|c|c|c|c|c|c|c|c|}
\hline $\mathrm{pH} \mathrm{H} \mathrm{H}_{2} \mathrm{O}$ & M.O. & $\mathrm{P}$ (Mehlich) & $\mathrm{SO}_{4}{ }^{2-}$ & $\mathrm{K}$ & $\mathrm{Ca}$ & $\mathrm{Mg}$ & $\mathrm{H}+\mathrm{Al}$ & $\mathrm{S}$ & $\mathrm{T}$ & $\mathrm{V}$ & $\mathrm{m}$ \\
\hline & $\mathrm{g} \mathrm{dm}^{-3}$ & -------mg dr & - & -- & 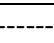 & $---m$ & $\left.\right|^{-3}-$ & ---- & & - & ---- \\
\hline 4,4 & 25 & 4 & 15 & 2,8 & 6 & 3 & 38 & 12 & 50 & 24 & 20 \\
\hline
\end{tabular}

1/ Analises realizadas conforme metodologias descritas em Teixeira et al. (2017). M.O. - matéria orgânica; S - Soma de bases; T - capacidade de troca catiônica em pH 7,0; V - saturação por bases; $\mathrm{m}$ - saturação por alumínio.

O delineamento experimental foi em blocos inteiramente casualizados, em esquema fatorial $2 \times 4$, com três repetições, sendo dois fertilizantes fosfatados (fertilizante mineral misto - FMM e superfosfato

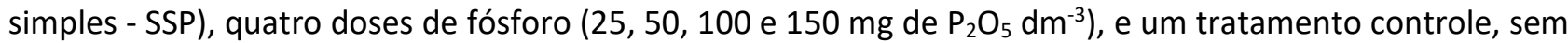
adubação fosfatada. Este delineamento foi montado duas vezes considerando duas condições de incubação (solo incubado com calcário e não incubado).

O FMM é um fertilizante mineral fosfatado misto, fonte de fósforo $\left(8,0 \%\right.$ de $\mathrm{P}_{2} \mathrm{O}_{5}$ total e $2,5 \%$ de $\mathrm{P}_{2} \mathrm{O}_{5}$ solúvel em ácido cítrico), enxofre $(4,0 \%$ de $\mathrm{S})$, cálcio (10,0\% de Ca), magnésio $(1,4 \%$ de $\mathrm{Mg}$ ) e silício (20\% de Si). É constituído de uma mistura de rocha fosfática sedimentar (extraída de jazidas de região de Arraias/TO, com $12 \%$ de $\mathrm{P}_{2} \mathrm{O}_{5}$ total), 'borra de enxofre' (que contém $60 \%$ de S-elementar) e calcário dolomítico. Possui efeito de correção de solo, tendo PRNT de aproximadamente $30 \%$.

O cálculo da necessidade de calagem para correção do solo foi feito de acordo Ribeiro et al. (1999). Apenas a metade do volume total foi corrigida. Após a incubação, as amostras de solo foram secas ao ar, peneiradas em peneira de malha de $4 \mathrm{~mm}$ e homogeneizadas separadamente. Ao final desta etapa, o solo incubado com calcário teve o pH determinado em 6,3. As unidades experimentais consistiram de vasos plásticos preenchidos com $3 \mathrm{~kg}$ de solo. Foi aplicado $0,1 \mathrm{~L}$ vaso-1 $^{-1}$ de uma solução nutritiva básica contendo nutrientes essenciais, sem fósforo, cálcio e magnésio. Sua composição encontra-se na Tabela 2. 
Tabela 2: Nutrientes, fontes e quantidades utilizadas para o preparo da solução nutritiva básica.

\begin{tabular}{lll}
\hline Nutriente & Fonte & Massa da fonte $(\mathrm{g}) \mathrm{L}^{-1}$ de solução \\
\hline $\mathrm{N}$ & $\mathrm{NH}_{4} \mathrm{NO}_{3}$ & 1,7647 \\
$\mathrm{~K}$ & $\mathrm{KCl}$ & 0,9034 \\
$\mathrm{Mg}$ & $\mathrm{MgCl}_{2} \cdot 6 \mathrm{H}_{2} \mathrm{O}$ & 2,5400 \\
$\mathrm{~B}$ & $\mathrm{H}_{3} \mathrm{BO}_{3}$ & 0,1369 \\
$\mathrm{Cu}$ & $\mathrm{CuSO}_{4} \cdot 5 \mathrm{H}_{2} \mathrm{O}$ & 0,1331 \\
$\mathrm{Fe}$ & $\mathrm{FeCl}_{3} \cdot 6 \mathrm{H}_{2} \mathrm{O}$ & 0,2246 \\
$\mathrm{Mn}$ & $\mathrm{MnCl}_{2} \cdot 4 \mathrm{H}_{2} \mathrm{O}$ & 0,3952 \\
$\mathrm{Mo}$ & $\mathrm{NaMoO}_{4} \cdot 2 \mathrm{H}_{2} \mathrm{O}$ & 0,0103 \\
$\mathrm{Zn}$ & $\mathrm{ZnSO}_{4} \cdot 7 \mathrm{H}_{2} \mathrm{O}$ & 0,5298 \\
\hline
\end{tabular}

No primeiro cultivo, foram semeadas oito sementes por vaso de milho (Zea mays L.) BRS1060. Aos 12 dias após a semeadura (DAS) foi feito o desbaste, permanecendo duas plantas por vaso. A umidade do solo foi mantida em uma faixa de 50 a $70 \%$ da capacidade de campo. Aos 24 dias após a semeadura, foi feita uma adubação de cobertura em todos os valos contendo $120 \mathrm{mg}^{\text {vaso-1 }}{ }^{-1}$ de $\mathrm{N}$ na forma de ureia, e $105 \mathrm{mg}$ vaso $^{-1}$ de $\mathrm{K}_{2} \mathrm{O}$ na forma de cloreto de potássio. Aos 50 DAS, foi feita a coleta da parte aérea das plantas de milho, que foram alocadas em sacos de papel e secas em estufa de ventilação forçada a 65ํㅡ até atingirem peso constante. Foi então determinada a massa seca da parte aérea (MSPA) e o acúmulo de P nos tecidos, seguindo metodologia proposta por Tedesco et al. (1995).

Logo após a coleta, foi realizada adubação com solução nutritiva com $70 \%$ da concentração aplicada no primeiro cultivo (Tabela 2) com exceção do $\mathrm{N}$, pois foram semeadas sementes de feijão inoculadas com uma estirpe de inoculante microbiano comercial (Rizóbio). Foram semeadas oito sementes por vaso de feijão (Phaseolus vulgaris L.) BRS Radiante. Aos 10 DAS foi realizado o desbaste, permanecendo duas plantas por vaso. Aos 25 DAS foi realizada a adubação de cobertura com as mesmas fontes e doses do plantio anterior. Aos 40 DAS, foi realizada a coleta da parte aérea das plantas de feijão. A coleta foi realizada exatamente da mesma forma que no primeiro cultivo.

Antecedendo o terceiro plantio, foi realizada adubação com solução nutritiva contento $70 \%$ da concentração da aplicada no primeiro cultivo (Tabela 2). A cultura e os tratos culturais foram os mesmos adotados no primeiro plantio, realizando-se a coleta aos 50 DAS. A eficiência relativa (ER) foi calculada para o fertilizante mineral misto e comparada à outra fonte de fertilizante usando a seguinte fórmula:

$$
E R=\frac{\text { Rendimento de FMM }- \text { Rendimento do controle }}{\text { Rendimento de SSP }- \text { Rendimento do controle }} \times 100
$$

Em que o Rendimento de FMM representa a produção de massa seca da parte aérea obtida com a aplicação do fertilizante mineral misto acumulada durante os três cultivos; Rendimento do controle é a produção de massa seca da parte aérea do tratamento sem fertilizante acumulada durante os três cultivos, e; o Rendimento de SSP é a produção de massa seca obtida pela aplicação do fertilizante superfosfato simples (SSP) acumulada durante os três cultivos.

Os dados obtidos foram separados de acordo com a condição de correção. Procedeu-se com o Teste de Kolmogorov-Smirnov para avaliar a distribuição dos dados. Em sequência, realizou-se a análise de variância como um fatorial entre fertilizantes e doses, excluindo tratamentos controle, sem aplicação de P. Quando significativos a $5 \%$ de probabilidade pelo teste $\mathrm{F}$, as médias dos fatores qualitativos (condição de solo e fertilizante) foram comparadas pelo teste de Tukey à $5 \%$, e os dados do fator quantitativo (doses de 
$\mathrm{P}_{2} \mathrm{O}_{5}$ ) foram submetidos a análise de regressão. A significância dos coeficientes de determinação foi analisada pelo teste $\mathrm{F}$ a $5 \%$.

\section{RESULTADOS E DISCUSSÃO}

A Tabela 3 apresenta o resumo da análise de variância da produção de massa seca (MSPA) e do acúmulo de $P$ da parte aérea (APPA) das plantas de milho e feijão nos três cultivos realizados em LVA incubado com calcário, em função da aplicação de diferentes fertilizantes e doses de $\mathrm{P}_{2} \mathrm{O}_{5}$. No primeiro cultivo houve a interação entre fertilizante e dose na produção de massa seca e acúmulo de $\mathrm{P}$ da parte aérea. No segundo cultivo, ocorreu diferença estatística entre os fertilizantes e entre as doses para MSPA e APPA. No terceiro cultivo se constatou diferença estatística entre os fertilizantes e entre as doses na MSPA e a interação entre fertilizante e dose no APPA.

Tabela 3: Resumo da análise de variância para a produção de massa seca da parte aérea (MSPA) e acúmulo de fósforo da parte aérea (APPA) em três cultivos sucessivos (1, 2 e 3), realizados em vasos com Latossolo Vermelho-Amarelo incubados com calcário, em função da aplicação de fontes e doses de fertilizantes fosfatados.

\begin{tabular}{|c|c|c|c|c|c|c|c|}
\hline \multirow{2}{*}{ FV } & \multirow{2}{*}{$\mathrm{GL}$} & \multicolumn{6}{|c|}{ Quadrado médio } \\
\hline & & MSPA $1^{\text {sqrt }}$ & APPA $1^{\text {sqrt }}$ & MSPA 2 & APPA 2 & MSPA 3 & APPA 3 \\
\hline Bloco & 2 & $0,31^{\text {ns }}$ & $0,27^{\text {ns }}$ & $1,10^{\text {ns }}$ & $1,16^{\mathrm{ns}}$ & $0,77^{\text {ns }}$ & $1,11^{\mathrm{ns}}$ \\
\hline Fertilizante (F) & 1 & $9,59^{*}$ & $9,30^{*}$ & $18,11^{*}$ & $100,29^{*}$ & $14,35^{*}$ & $79,68^{*}$ \\
\hline Dose (D) & 3 & $2,54^{*}$ & $2,29^{*}$ & $3,54^{*}$ & $32,81^{*}$ & $12,25^{*}$ & $34,95^{*}$ \\
\hline$F \times D$ & 3 & $1,81^{*}$ & $1,44^{*}$ & $2,23^{\text {ns }}$ & $5,59^{\text {ns }}$ & $2,63^{\text {ns }}$ & $7,46^{*}$ \\
\hline Erro & 14 & 0,10 & 0,10 & 1,04 & 2,86 & 0,87 & 1,57 \\
\hline CV (\%) & & 15,31 & 15,88 & 29,47 & 29,95 & 18,90 & 19,66 \\
\hline
\end{tabular}

${ }^{\mathrm{ns}}=$ não significativo; ${ }^{*}$ = significativo a $0,05 \%$ de probabilidade pelo teste $\mathrm{F} .{ }^{\text {sqrt }}=$ dados transformados em raiz quadrada de $Y+1$.

No primeiro cultivo em LVA incubado com calcário, houve aumento linear da produção de MSPA em função do aumento da dose de $\mathrm{P}$ aplicada na forma de SSP. A aplicação de doses crescentes de $\mathrm{P}_{2} \mathrm{O}_{5}$ na forma de FMM não influenciou a MSPA, sendo o SSP superior estatisticamente (Figura 1). No segundo cultivo, SSP e FMM proporcionaram incrementos na MSPA. Observou-se maiores valores de MSPA quando se aplicou SSP como fonte de P. No terceiro cultivo, ambos fertilizantes proporcionaram incrementos de MSPA em resposta ao aumento da dose de P. O SSP foi estatisticamente mais eficiente que FMM na produção de MSPA em todos os cultivos. Quando se utilizam fosfatos naturais, os quais se beneficiam da acidez do solo para sua solubilização, observa-se decréscimo na solubilidade com a aplicação de calcário (SOUZA et al., 2003). Desta forma, a incubação prévia do solo diminuiu a eficiência do FMM, especialmente no primeiro ciclo, onde não se verificou efeito da aplicação de doses crescentes de P na MSPA (Figura 1) e no APPA (Figura 2).

No primeiro cultivo realizado em solo corrigido, o APPA aumentou de maneira linear em resposta ao aumento da dose de $\mathrm{P}$ aplicado na forma de SSP, enquanto que a aplicação de FMM não proporcionou diferença nos valores de APPA em resposta ao aumento da dose (Figura 2). Nos cultivos seguintes, o modelo que melhor se ajustou ao aumento do APPA em resposta à aplicação de SSP foi o modelo polinomial de ordem 2, enquanto que para FMM o modelo linear foi o mais apropriado. No segundo e terceiro cultivos, o fertilizante SSP proporcionou maiores valores de APPA em comparação ao FMM. A partir do segundo ciclo, alguma acidez foi gerada no solo o que proporcionou liberação do P do FMM, ainda que de forma menos 
intensa quando do uso do SSP.
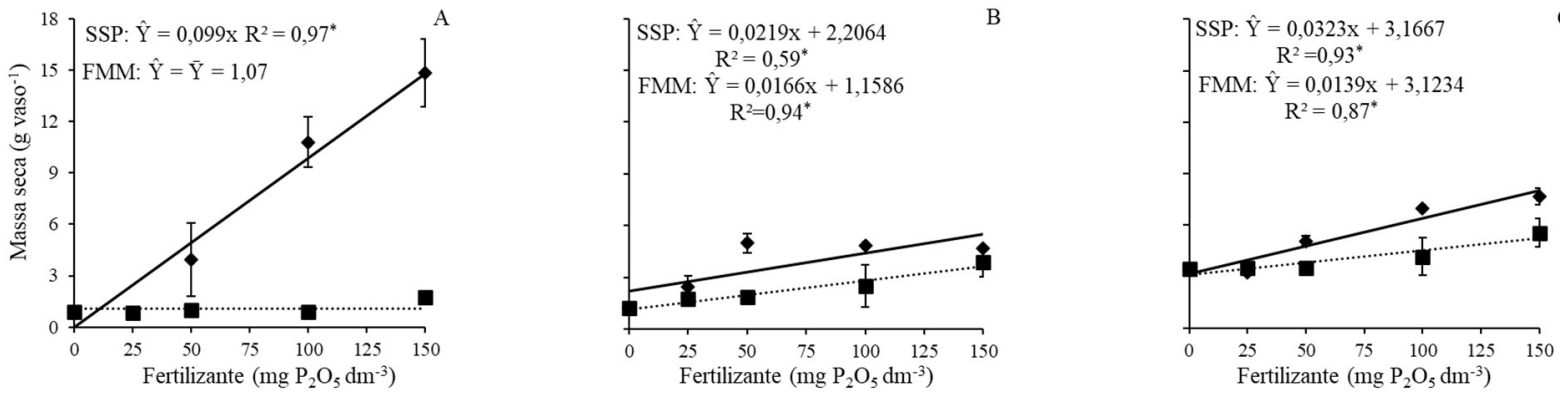

- SSP.

aMM

Figura 1: Produção de massa seca da parte aérea (MSPA) no primeiro (A), segundo (B) e terceiro cultivos (C) de plantas de milho ( 1 ㅇ e 3 ㅇ cultivos) e feijão (2ㅇ cultivo), crescidas em amostras de um Latossolo Vermelho-Amarelo textura argilosa incubadas com calcário, em função da aplicação de doses crescentes de $\mathrm{P}$, na forma de superfosfato simples

(SSP) e fertilizante mineral misto (FMM). ${ }^{*}=$ significativo a $5 \%$ de probabilidade pelo teste $\mathrm{F}$. As barras verticais representam o erro padrão da média.
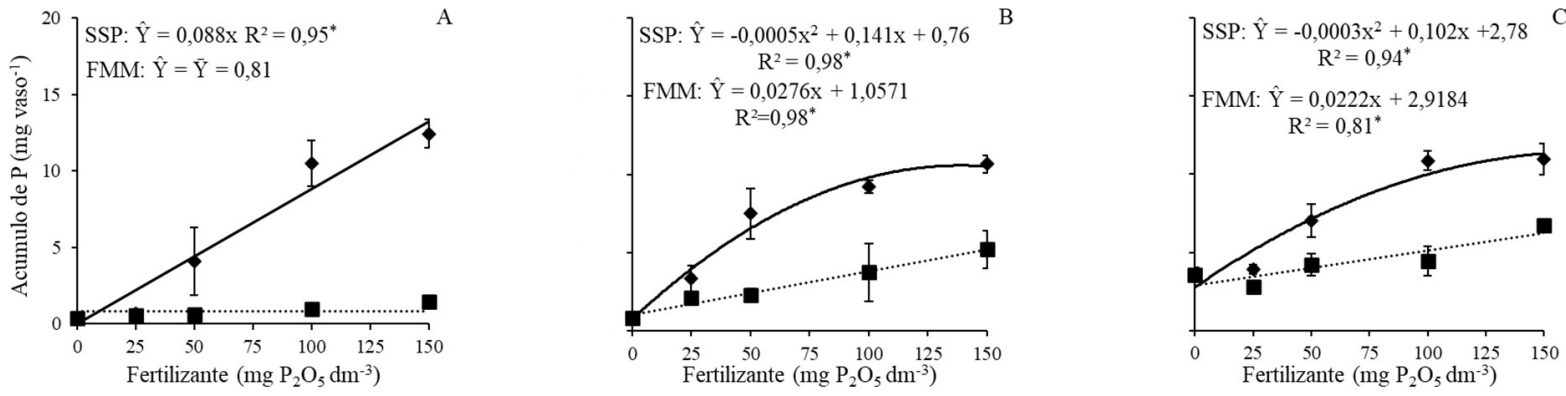

$\bullet$ SSP.

DFMM

Figura 2: Acúmulo de $P$ no primeiro (A), segundo (B) e terceiro cultivos (C) de plantas de milho (10 e 3은 cultivos) e feijão ( 2 - cultivo), crescidas em amostras de um Latossolo Vermelho-Amarelo textura argilosa incubadas com calcário, em função da aplicação de doses crescentes de $P$, na forma de superfosfato simples (SSP) e fertilizante mineral misto (FMM). * . Significativo a 0,05 de probabilidade pelo teste $F$. As barras verticais representam o erro padrão da média.

\section{A}

Tabela 4 apresenta o resumo da análise de variância da produção de massa seca e do acúmulo de $\mathrm{P}$ da parte aérea das plantas de milho e feijão nos três cultivos, realizados em LVA não incubado com calcário, em função da aplicação de diferentes doses de fertilizantes fosfatados. No primeiro cultivo observou-se a interação entre fertilizante e dose na MSPA, e significância entre doses e fertilizantes para APPA. No segundo cultivo, não houve diferença estatística entre as variáveis independentes em relação à MSPA. Porém, o APPA foi influenciado pelo fertilizante e pela dose. No terceiro cultivo ocorreu significância de dose na MSPA e no APPA.

No primeiro cultivo em solo não incubado com calcário, observou-se aumento da MSPA em resposta à aplicação de doses crescentes de P para as duas fontes (Figura 3). $O$ aumento foi mais pronunciado quando a dose de $\mathrm{P}$ foi aplicada na forma de SSP. No segundo e terceiro cultivos, não houve diferença entre os fertilizantes, sendo observado comportamento quadrático da MSPA em resposta ao aumento da dose de $\mathrm{P}_{2} \mathrm{O}_{5}$. 
Tabela 4: Resumo da análise de variância para a produção de massa seca da parte aérea (MSPA) e acúmulo de fósforo da parte aérea (APPA) em três cultivos sucessivos realizados em vasos com amostras de Latossolo Vermelho-Amarelo não incubado com calcário, em função da aplicação de fontes e doses de fertilizantes fosfatados.

\begin{tabular}{llllllll}
\hline \multirow{2}{*}{ FV } & \multirow{2}{*}{ GL } & \multicolumn{2}{l}{ Quadrado médio } & & & \\
\cline { 3 - 8 } & & MSPA 1 & APPA 1 & MSPA 2 & APPA 2 & MSPA 3 & APPA 3 \\
\hline Bloco & 2 & $1,27^{\text {ns }}$ & $4,38^{\text {ns }}$ & $1,73^{\text {ns }}$ & $8,51^{\text {ns }}$ & $0,00^{\text {ns }}$ & $0,75^{\text {ns }}$ \\
Fertilizante (F) & 1 & $76,61^{*}$ & $57,38^{*}$ & $1,78^{\text {ns }}$ & $19,76^{*}$ & $0,33^{\text {ns }}$ & $1,40^{\text {ns }}$ \\
Dose (D) & 3 & $60,62^{*}$ & $79,70^{*}$ & $1,21^{\text {ns }}$ & $65,94^{*}$ & $10,48^{*}$ & $49,89^{*}$ \\
Fx D & 3 & $6,97^{*}$ & $1,27^{\text {ns }}$ & $0,34^{\text {ns }}$ & $1,67^{\text {ns }}$ & $1,02^{\text {ns }}$ & $6,92^{\text {ns }}$ \\
Erro & 14 & 2,09 & 5,14 & 1,19 & 4,04 & 0,60 & 3,35 \\
\hline CV (\%) & & 14,87 & 19,85 & 23,17 & 20,51 & 14,77 & 24,51 \\
\hline
\end{tabular}

${ }^{\mathrm{ns}}=$ não significativo a $5 \%$ de probabilidade; ${ }^{*}$ = significativo a $5 \%$ de probabilidade pelo teste $\mathrm{F}$.
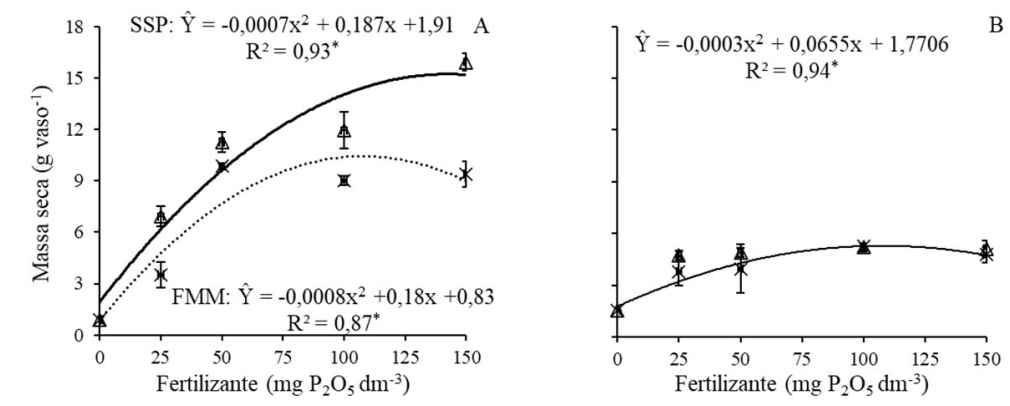

$\triangle \mathrm{SSP}$
B

$\times \mathrm{FMM}$

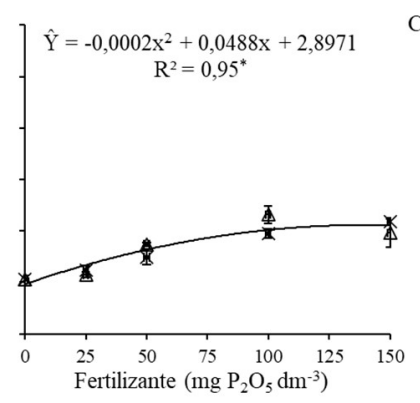

Figura 3. Produção de massa seca da parte aérea no primeiro $(A)$, segundo $(B)$ e terceiro cultivos (C) de plantas de milho ( 1 ㅇ e 3 o cultivos) e feijão ( 2 o cultivo) adubadas com doses crescentes de $P$, na forma de superfosfato simples (SSP) e fertilizante mineral misto (FMM), crescidas em amostras de um Latossolo Vermelho-Amarelo textura argilosa não incubadas com calcário. ${ }^{*}=$ significativo a 0,05 de probabilidade pelo teste $\mathrm{F}$. As barras verticais representam o erro padrão da média

O modelo que melhor se ajustou para o APPA em resposta ao aumento da dose de $\mathrm{P}$ foi o polinomial de ordem 2, em todos os cultivos (Figura 4). No primeiro e segundo cultivos, o SSP proporcionou maiores APPA em relação ao FMM. A maior diferença entre os fertilizantes foi encontrada no primeiro cultivo, diminuindo no segundo até que no terceiro a eficiência foi similar.
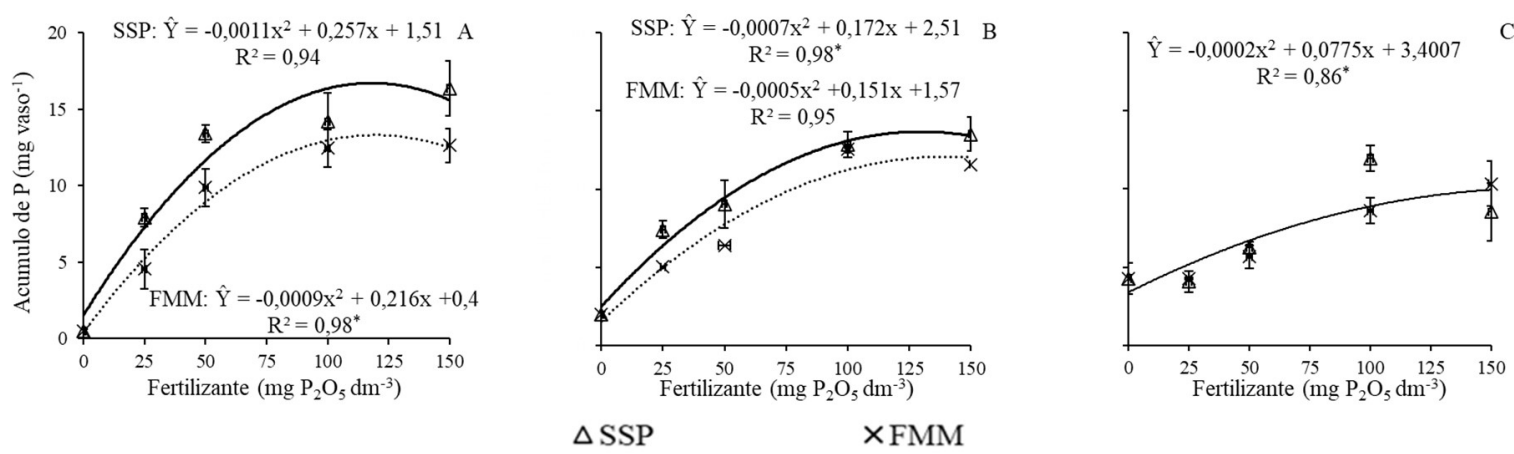

Figura 4: Acúmulo de $P$ no primeiro (A), segundo (B) e terceiro cultivos (C) de plantas de milho (10 e 3 o cultivos) e feijão ( 2 o cultivo) adubadas com doses crescentes de $P$, na forma de superfosfato simples (SSP) e fertilizante mineral misto (FMM), crescidas em amostras de um Latossolo Vermelho-Amarelo textura argilosa não incubadas com calcário.

${ }^{*}=$ significativo a 0,05 de probabilidade pelo teste $\mathrm{F}$. As barras verticais representam o erro padrão da média.

A Tabela 5 apresenta o resumo da análise de variância da massa seca da parte aérea (MSPAT) e do acúmulo de $\mathrm{P}$ da parte aérea (APPAT) totalizados durante os três cultivos sequenciais realizados em amostras de LVA incubadas e não incubadas com calcário. No solo incubado com calcário, constatou-se a interação entre fertilizante e dose para as duas variáveis dependentes, MSPAT e APPAT. No solo não incubado com 
calcário houve diferença significativa entre as doses e os fertilizantes aplicados.

Tabela 5: Resumo da análise de variância para a massa seca da parte aérea (MSPAT) e acúmulo de fósforo da parte aérea (APPAT) totalizados nos três cultivos sequenciais, realizados em vasos com amostras de Latossolo VermelhoAmarelo incubadas e não incubadas com calcário, em função da aplicação de fontes e doses de fertilizantes fosfatados.

\begin{tabular}{|c|c|c|c|c|c|}
\hline \multirow{2}{*}{ FV } & \multirow{2}{*}{$\mathrm{GL}$} & \multicolumn{2}{|c|}{ Solo incubado } & \multicolumn{2}{|c|}{ Solo não incubado } \\
\hline & & MSPAT & APPAT & MSPAT & APPAT \\
\hline Bloco & 2 & $18,30^{\text {ns }}$ & $8,14^{\mathrm{ns}}$ & $5,40^{\text {ns }}$ & $29,05^{\mathrm{ns}}$ \\
\hline Fertilizante (F) & 1 & $572,13^{*}$ & $1173,91^{*}$ & $113,62^{*}$ & $174,47^{*}$ \\
\hline Dose (D) & 3 & $191,25^{*}$ & $341,61^{*}$ & $134,28^{*}$ & $549,45^{*}$ \\
\hline$F \times D$ & 3 & $80,11^{*}$ & $119,76^{*}$ & $2,68^{\text {ns }}$ & $2,13^{\text {ns }}$ \\
\hline Erro & 14 & 2,50 & 11,97 & 2,27 & 9,86 \\
\hline CV (\%) & & 7,56 & 21,88 & 7,66 & 10,94 \\
\hline
\end{tabular}

${ }^{n s}=$ não significativo; ${ }^{*}=$ significativo a $5 \%$ de probabilidade pelo teste $\mathrm{F}$.

No solo incubado com calcário, houve resposta quadrática da MSPAT em função do aumento da dose de Paplicado na forma de SSP e linear para o FMM. O APPA aumentou de forma linear em função do aumento da dose de P aplicada na forma de FMM e comportou-se de maneira quadrática quando as doses foram aplicadas na forma de SSP, sendo que este fertilizante proporcionou maiores valores de MSPAT e APPT em relação ao FMM na condição de solo incubado com calcário. (Figura 5). No solo não incubado, ambos os fertilizantes promoveram incremento na MSPAT e no APPAT em resposta ao aumento da dose de fertilizante. As respostas ao aumento da dose apresentaram comportamento quadrático para MSPAT e APPAT. Embora as diferenças entre o desempenho dos fertilizantes tenham sido menos pronunciadas quando não houve incubação, nessa condição, ainda sim o SSP apresentou melhor desempenho na produção de MSPAT e no APPAT.

Solo incubado
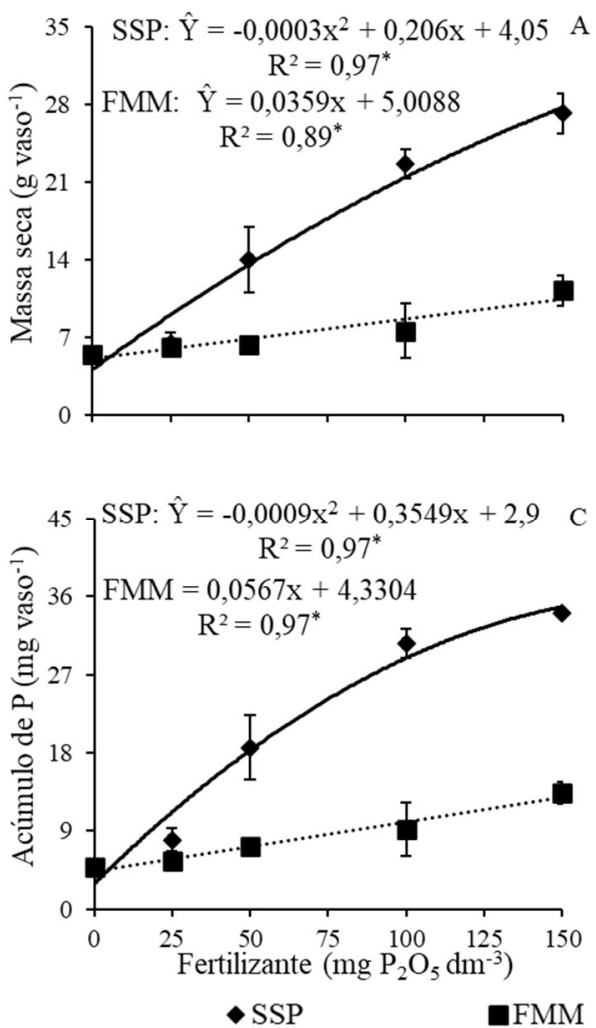

Solo não incubado

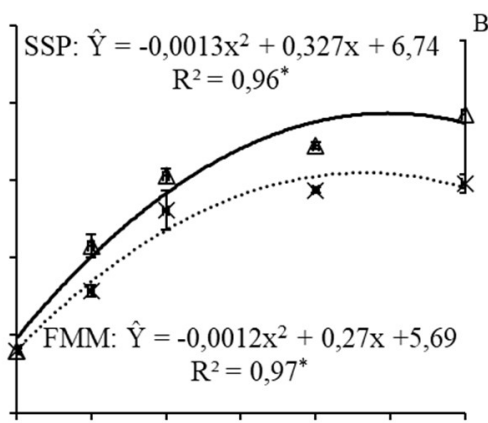

SSP $\cdot \hat{\mathrm{Y}}=-0,0035 \mathrm{x}^{2}+0,666 \mathrm{x}+5,79$

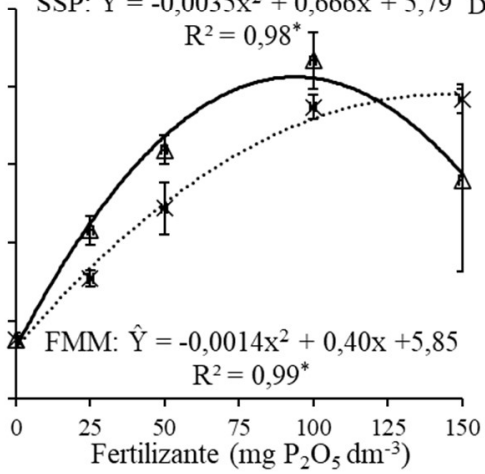

$\triangle \mathrm{SSP}$

$\times$ FMM

Figura 5: Produção de massa seca da parte aérea (MSPA) (A e $B$ ) e conteúdo de $P(C$ e $D$ ) na parte aérea de plantas de milho (1ㅇe e 3 cultivos) e feijão ( 2 - cultivo) cultivadas em amostras de Latossolo Vermelho-Amarelo textura argilosa, incubadas com calcário e não incubadas , acumulados durante três cultivos sucessivos, em função da aplicação de doses crescentes de $P$, na forma de superfosfato simples (SSP) e fertilizante mineral misto (FMM). ${ }^{*}=$ significativo a 0,05 de probabilidade pelo teste F. As barras verticais representam o erro padrão da média. 
A Figura 6 apresenta a eficiência relativa do FMM em comparação ao SSP. Em todas as doses e condições de incubação, o FMM teve desempenho inferior ao SSP, porém a incubação do solo comprometeu mais fortemente a produção de matéria quando do uso do FMM em relação ao SSP resultado em ER bem inferior, nas doses de 50, 100 e $150 \mathrm{mg}$ de $\mathrm{P}_{2} \mathrm{O}_{5} \mathrm{dm}^{-3}$, em relação ao solo incubado.


Figura 6: Eficiência relativa do fertilizante mineral misto comparado a superfosfato simples, em relação a produção de matéria seca da parte aérea, aplicados em um Latossolo Vermelho-Amarelo incubado com calcário e não incubado.

A baixa concentração de prótons e a concentração elevada de $\mathrm{Ca}^{2+}$ tendem a promover desequilíbrio na reação de dissolução de fosfatos de rocha, reduzindo a liberação de $P$ do fertilizante (RAJAN et al., 2004). Além de possuir PRNT de 30\%, o FMM também tem em sua composição $10 \%$ de Ca. Devido à pequena concentração de $\mathrm{P}_{2} \mathrm{O}_{5}$ desse fertilizante ( $2,5 \%$ solúvel em ácido cítrico), a quantidade total de fertilizante a ser aplicada por área é relativamente grande quando comparado a fontes mais concentradas. Se considerarmos que o teor de $\mathrm{P}_{2} \mathrm{O}_{5}$ solúvel em citrato neutro de amônio é de $18 \%$ no SSP e compararmos com o teor de 2,5\% de $\mathrm{P}_{2} \mathrm{O}_{5}$ em FMM, a massa aplicada em uma área qualquer para fornecer uma determinada dose de $\mathrm{P}$ na forma de FMM é 7,2 vezes maior que a de SSP. Esse grande volume aplicado pode adicionar elevadas quantidades de $\mathrm{Ca}$ ao solo, além de elevar o pH do meio. Quando o pH do solo excede 5,5, a maior parte do fosfato reage com o cálcio, resultando em uma liberação lenta do P disponível para as plantas (MILIĆ et al., 2019). Foi constatado no presente trabalho que, após a incubação com calcário, o solo apresentava pH 6,3. Portanto, a correção prévia do solo diminuiu significativamente a eficiência do FMM. A liberação de $P$, do FMM, em formas assimiláveis para as plantas, foi aquém daquelas observadas com o SSP, principalmente na condição de solo incubado, refletindo na ausência de incremento na produção de MSPAT e do APPAT em resposta ao aumento da dose daquele fertilizante nos solos corrigidos com calcário.

Avaliando a eficiência de fosfatos de rocha em solo com elevado teor de cálcio trocável $(13,5 \mathrm{cmol} c$ $\mathrm{dm}^{-3}$ ), Souza et al. (2014) constataram maiores teores de P em folhas de milho adubado com superfosfato triplo, comparado a adubação com fosfato natural. Os autores ainda concluíram, que quanto maior a solubilidade da fonte testada na adubação fosfatada corretiva, menor foi a necessidade de reposição de fósforo no sulco de plantio no ano posterior.

Para a adubação fosfatada corretiva, com aplicação da dose recomendada a lanço com incorporação, os fosfatos naturais reativos apresentam eficiência agronômica inferior, no ano da aplicação, em relação às fontes solúveis, mas seu efeito residual é equivalente ou mesmo superior às fontes solúveis nos anos subsequentes (SOUZA et al., 2016). No caso de culturas perenes com desenvolvimento mais gradual, o efeito 
residual proporcionado pelo FMM pode se tornar benéfico. Rodrigues et al. (2016), avaliando a produtividade de eucalipto aos 18 meses de idade na região do cerrado, em resposta à aplicação de cálcio, constataram que na ausência de calcário, a aplicação de fosfato natural reativo no sulco de subsolagem aumentou a produção de fuste em $26 \%$ em relação ao monoamônio fosfato (MAP). Os autores atribuem o desempenho superior do fosfato natural ao Ca existente em sua formulação, superando o efeito do $\mathrm{N}$ contido no MAP. Vale destacar que tal resultado foi obtido num solo sem calagem, e com baixos teores de Ca.

A adição de enxofre elementar proporciona redução do $\mathrm{pH}$, ao ser oxidado por microrganismos (Thiobacillus), facilitando a solubilidade de fosfatos naturais (STAMFORD et al., 2004). Porém, ao avaliar a eficiência de superfosfato triplo e fosfato natural reativo - Gafsa, associados ao enxofre elementar na cultura do milho em condições de campo, Frandoloso et al. (2010) não constataram diferença significativa no teor de $\mathrm{P}$ no tecido foliar com a adição de $30 \mathrm{~kg} \mathrm{ha}^{-1}$ de $\mathrm{S}^{0}$. A adição de $\mathrm{S}^{0}$ à formulação do $\mathrm{FMM}$ não proporcionou solubilidade satisfatórias ao fertilizante em condições de casa de vegetação, ficando nítida a influência da calagem sobre a solubilidade do fertilizante avaliado.

\section{CONCLUSÕES}

O SSP foi mais eficiente que FMM na produção de massa seca e no acúmulo de P. As maiores respostas da MSPA e do APPA em relação ao aumento da dose do FMM foram observadas em solo não incubado com calcário, porém foram aquém daquelas observadas para SSP.

A eficiência relativa de FMM foi severamente reduzida devido à incubação do solo com calcário. Portanto, no curto prazo, a aplicação do FMM em solos corrigidos deve ser feita associada a alguma fonte solúvel de P.O SSP obteve desempenho semelhante na MSPA e APPA tanto em condições de solo incubado quanto de solo não incubado. No curto prazo, a aplicação de FMM deve ser feita associada a uma fonte solúvel, especialmente quando aplicado em solos já corrigidos previamente.

AGRADECIMENTOS: À Embrapa, ao Departamento de Solos da UFRRJ, e ao Conselho Nacional de Desenvolvimento Científico e Tecnológico (CNPq), pelo apoio logístico e financeiro à pesquisa.

\section{REFERÊNCIAS}

ANDA. Associação Nacional para Difusão de Adubos. Anuário estatístico do setor de fertilizantes 2018. São Paulo: ANDA, 2019

ASHLEY, K.; CORDELL, D.; MAVINIC, D.. A brief history of phosphorus: from the philosopher's stone to nutrient recovery and reuse. Chemosphere, v.84, n.6, p.737-746, 2011. DOI:

https://doi.org/10.1016/j.chemosphere.2011.03.001

BRAOS, L. B.; CRUZ, M. C. P.; FERREIRA, M. E.; KUHNEN, F.. Organic phosphorus fractions in soil fertilized with cattle manure. Revista Brasileira de Ciência do Solo, v.39, n.1, p.140-150, 2015. DOI:

https://doi.org/10.1590/01000683rbcs20150137
BROGGI, F.; FREIRE, F. J.; FREIRE, B. G. S.; NASCIMENTO, C. W. A; OLIVEIRA, A. C.. Avaliação da disponibilidade, adsorção e níveis de fósforo em diferentes solos. Revista Ceres, v.57, n.2, p.247-252, 2010. DOI: https://doi.org/10.1590/s0034737X2010000200017

COOPER, J.; LOMBARDI, R.; BORDMAN, D.; CARLIELLMARQUET, $C$.. The future distribution and production of global phosphate rock reserves. Resources, Conservation and Recycling, v.57, p.78-86, 2011. DOI: https://doi.org/10.1016/i.resconrec.2011.09.009

FRANDOLOSO, J. F.; LANA, M. C.; FONTANIVA, S.; CZYEZA, R. V.. Eficiência de adubos fosfatados associados ao enxofre elementar na cultura do milho. Revista Ceres, v.57, n.5, 
p.686-694, 2010. DOI: http://dx.doi.org/10.1590/S0034$\underline{737 \times 2010000500019}$

GEISSLER, B.; STEINER, G.; MEW, M. C.. Clearing the fog on phosphate rock data: Uncertainties, fuzziness, and misunderstandings. Science of the Total Environment, v.642, p.250-263, 2018. DOI: https://doi.org/10.1016/j.scitotenv.2018.05.381

KOPPELAAR, R. H. E. M.; WEIKARD, H. P.. Assessing phosphate rock depletion and phosphorus recycling options. Global Environmental Change, v.23, p.1454-1466, 2013. DOI: https://doi.org/10.1016/j.gloenvcha.2013.09.002

LEGHARI, S. J.; BURIRO, M.; JOGI, Q.; KANDHRO, M. N.; LEGHARI, A. J.. Depletion of phosphorus reserves, a big threat to agriculture: challenges and opportunities. Science International, v.28, n.3, p.2697-2702, 2016

MILIĆ, S.; NIKOV, J.; ZEREMSK, T.; LATKOVIĆ, D.; ŠEREMŠIĆ, S.; RADOVANOVIĆ, V.; ŽARKOVIĆ, B.. Soil fertility and phosphorus fractions in a calcareous chernozem after a longterm field experiment. Geoderma, v.339, p.9-19, 2019. DOI: https://doi.org/10.1016/i.geoderma.2018.12.017

NOVAIS, R. F.; SMYTH, T. J.. Fósforo em solo e planta em condições tropicais. Viçosa: UFV, 1999.

RAJAN, S. S. S.; CASANOVA, E.; TRUONG, B.. Factors affecting the agronomic effectiveness of phosphate rocks, with a casestudy analysis. In: ZAPATA, F.; ROY, R. N.. Use of phosphate rocks for sustainable agriculture. Roma: FAO, 2004. p.41-57.

RIBEIRO, A. C.; RIBEIRO, A. C.; GUIMARÃES, P. T. G.; ALVAREZ V. V. H.. Recomendações para uso de corretivos e fertilizantes em Minas Gerais: 5a aproximação. Viçosa: CFSEMG, 1999.

RODRIGUES, F. A. V.; ALVARES V., V. H.; BARROS, N. F.; SILVA, I. R.; NEVES, J. C. L.. Produtividade de eucalipto aos 18 meses de idade, na região do cerrado, em resposta à aplicação de cálcio, via calagem e gesso agrícola. Scientia Forestalis, v.44, n.109, p.67-74, 2016. DOI: dx.doi.org/10.18671/scifor.v44n109.06
SANTOS, H. G.; JACOMINE, P. K. T; ANJOS, L. H. C. ; OLIVEIRA, V. A.; LUMBRERAS, J. F.; COELHO, M. R.; ALMEIDA, J. A. ; ARAUJO FILHO, J. C.; OLIVEIRA, J. B. ; CUNHA, T. J. F. Brazilian soil classification system. 5 ed. Brasília: Embrapa, 2018.

SOUSA, D. M. G.; LOBATO, E.. Adubação fosfatada em solos da região do cerrado. Informações Agronômicas, n.102, p.116, 2003.

SOUZA, R. M.; SOBRAL, L. F.; VIÉGAS, P. R. A.; OLIVEIRA JUNIOR, A.; CARVALHO, M. C. S.. Eficiência agronômica de fosfatos de rocha em solo com elevado teor de cálcio trocável. Revista Brasileira de Ciência do Solo, v.38, p.18161825, 2014. DOI: https://doi.org/10.1590/S0100$\underline{06832014000600016}$

SOUSA, D. M. G.; NUNES, R. S.; REIN, T. A.; SANTOS JUNIOR, J. D. G.. Manejo do fósforo na região do Cerrado. In: FLORES, R. A.; CUNHA, P. P.. Práticas de manejo do solo para adequada nutrição de plantas no Cerrado. Goiânia: UFG, 2016. p.291-358.

STAMFORD, N. P.; MOURA, A. M. M. F.; SANTOS, K. S.; SANTOS, P. R.. Atuação de Acidithiobacillus na solubilização de fosfato natural em solo de tabuleiro cultivado com Jacatupé (Pachyrhizus erosus). Revista Brasileira de Ciência do Solo, v.25, p.75-83, 2004. DOI: https://doi.org/10.1590/S0100-06832004000100008

TEDESCO, M. J.; GIANELLO, C.; BISSANI, C. A.; BOHNEN, H.; VOLKWEISS, S. J.. Análise de solo, plantas e outros materiais. 2 ed. Porto Alegre: Departamento de Solos da Universidade Federal do Rio Grande do Sul, 1995.

TEIXEIRA, P. C.; DONAGEMMA, G. K.; FONTANA, A.; TEIXEIRA, W. G.. Manual de métodos de análise de solo. 3 ed. Brasília: Embrapa, 2017.

USGS. United States Geological Survey. Mineral commodity summaries 2020: U.S. Geological Survey, 2020.

A CBPC - Companhia Brasileira de Produção Científica (CNPJ: 11.221.422/0001-03) detém os direitos materiais desta publicação. Os direitos referem-se à publicação do trabalho em qualquer parte do mundo, incluindo os direitos às renovações, expansões e disseminações da contribuição, bem como outros direitos subsidiários. Todos os trabalhos publicados eletronicamente poderão posteriormente ser publicados em coletâneas impressas sob coordenação da Sustenere Publishing, da Companhia Brasileira de Produção Científica e seus parceiros autorizados. Os (as) autores (as) preservam os direitos autorais, mas não têm permissão para a publicação da contribuição em outro meio, impresso ou digital, em português ou em tradução. 